\title{
ANALYSIS OF TSUNAMI EVACUATION CAUSED BY THE GREAT EAST JAPAN EARTHQUAKE: A CASE STUDY OF IBARAKI PREFECTURE
}

\author{
Makoto Tamura ${ }^{1}$, Yu Tabayashi ${ }^{2}$, Frank Hiroshi Ling ${ }^{3}$, \\ Kiyotake Ajima ${ }^{4}$, Nobuo Mimura ${ }^{5}$, and Kazuya Yasuhara ${ }^{6}$ \\ ${ }^{1}$ Associate professor, Institute for Global Change Adaptation Science, Ibaraki University, \\ Ibaraki, Japan, Ph.D., tamura@mx.ibaraki.ac.jp \\ ${ }^{2}$ Project assistant professor, Center for Research In Isotopes and Environmental Dynamics, \\ University of Tsukuba, Ibaraki, Japan, Ph.D. \\ ${ }^{3}$ Researcher, Institute for Global Change Adaptation Science, Ibaraki University, Ibaraki, Japan, Ph.D. \\ ${ }^{4}$ Researcher, Institute for Global Change Adaptation Science, Ibaraki University, Ibaraki, Japan, M.A. \\ ${ }^{5}$ Professor, Institute for Global Change Adaptation Science, Ibaraki University, Ibaraki, Japan, Dr.Eng. \\ ${ }^{6}$ Member of JAEE, Professor Emeritus, Institute for Global Change Adaptation Science, Ibaraki \\ University, Ibaraki, Japan, Dr.Eng.
}

\begin{abstract}
This study characterizes evacuation behavior in Ibaraki Prefecture in the aftermath of the Great East Japan Earthquake and tsunamis based on geographic information, questionnaires, and interview surveys. We identified several factors on which the starting time of evacuation depended, including awareness of evacuation warnings, understanding of anticipated tsunami inundation areas (hazard maps), and distance from anticipated inundation areas. We found that those who were aware of evacuation sites, hazard maps and/or anticipated inundation areas maps, and who lived in inundated areas tended to evacuate earlier. Conversely, many residents delayed their evacuation because they chose to go home and take care of their family first. To improve future responses to likely threats, evacuation behavior and local disaster management plans must be reviewed based on the knowledge gained from this disaster.
\end{abstract}

Key Words: Tsunami, evacuation, Ibaraki, Great East Japan Earthquake

\section{INTRODUCTION}

Earthquakes have long been feared in Japan. While there is extensive literature on the seismic movement and physical mechanisms of earthquakes, only a handful of studies address evacuation procedures, especially for tsunamis, which can result in a large number of casualties. The current research on Tsunami evacuation is broadly divided into two categories: (1) interview and questionnaire surveys, and (2) numerical studies based on statistical data or computer simulations such as multi-agent simulation.

Very few studies of the first type of tsunami research have been conducted. Lachman et al. (1961) examined the damage in Hilo, Hawaii Island wrought by the 1960 Chile Earthquake. More than half the respondents did not evacuate, although $89 \%$ heard the tsunami alert. Lachman et al. (1961) note that a certain level of education and past experiences may help residents understand the significance of warning systems. This assertion was based on the fact that $69 \%$ of long term, native residents of 
Hawaii Island were more likely to evacuate than more recent settlers. Furthermore, they highlighted that some myths, those focusing on the gods, may facilitate evacuation during natural disasters. Tanaka et al. (2006) found that despite the tsunami alert, $84 \%$ of residents in Aichi Prefecture, Japan, did not evacuate, basing their decision on their past experiences of the September 2004 Tsunami.

In contrast, the second type of tsunami evacuation research, which employs numerical data and simulations, focuses mainly on Japan and the 2004 Sumatra Earthquake in Indonesia and Thailand. Post et al. (2009) assessed the environmental and demographic impact on evacuation speed using a Cost Distance Weighting GIS approach. It showed that approximately 4.35 million Indonesians live in tsunami-endangered areas on the southern coasts of Sumatra, Java, and Bali, and are 20 to 150 minutes from a tsunami-safe area. It also estimated a worst-case tsunami scenario for Kuta (Bali), estimating 25,000 casualties with an optimal response time (direct evacuation when receiving a tsunami warning), and 120,000 for minimal response time (no evacuation). Furthermore, Wegscheider et al. (2011) tried to raise awareness within communities using GIS vulnerability maps in Bali, Indonesia. Through multi-agent simulation, Saito and Kagami (2005) constructed an evacuation behavior model for the Okushiri Island Earthquake off the Southwest coast of Hokkaido in 1993.

This study examines post-tsunami evacuation in Ibaraki Prefecture following the Great East Japan Earthquake (or 2011 off the Pacific coast of Tohoku Earthquake). The study aims to identify the relationship between evacuation behavior and the perception of anticipated inundation, and to discuss prompt and efficient evacuation. This study analyzes evacuee behavior from multiple perspectives, including information on and recognition of anticipated inundation areas (hazard maps) prepared before the disaster. There are two significant aspects with regard to the methodology and subject of this study. First, it combines a questionnaire survey on residents and GIS analysis. Second, the study surveys Ibaraki Prefecture, which has not yet been examined.

At 14:46 on March 11, 2011, an earthquake located off the Pacific coast of Tohoku occurred, triggering massive tsunamis measuring up to $10 \mathrm{~m}$ in height and $40.5 \mathrm{~m}$ in maximum run-up height. The disaster wrought devastating damage, including 15,884 deaths and 2,640 missing, according to the National Police Agency on January 10, 2014 (Mimura et al. 2011; Tamura 2012). Unlike the Great Hanshin and Awaji Earthquakes of 1995, in which about $80 \%$ of victims suffocated or were crushed to death beneath collapsing structures, more than $90 \%$ of the deaths in the 2011 disaster were presumed to be by drowning due to tsunamis. Furthermore, with $65 \%$ of the identified victims aged 60 years and older, it is clear that many elderly people were unable to escape the tsunamis.

As well as empirical studies conducted outside Japan, many papers have addressed the scientific aspects of and the tsunami damage wrought by the Great East Japan Earthquake. For example, Suppasri et al. (2012) described the characteristics of the damage caused by the tsunami in Miyagi Prefecture, and Lovholt et al. (2012) conducted tsunami inundation simulations. In Ibaraki Prefecture, Nobuoka et al. (2011) measured tsunami height along the coast.

On the topic of tsunami evacuation, most research has been carried out by administrative agencies, while only a few academic studies have been conducted. Organizations such as the Central Disaster Prevention Council (2011) conducted large-scale investigations on tsunami evacuations in three Tohoku prefectures (Iwate, Miyagi, and Fukushima), but their investigations did not extend to Ibaraki. After the Central Disaster Prevention Council (2011), the Ministry of Land, Infrastructure, Transport, and Tourism (MLIT) (2013) investigated and developed archives (http://fukkou.csis.u-tokyo.ac.jp) of evacuation procedures in 62 municipalities in 6 prefectures (Aomori, Iwate, Miyagi, Fukushima, Ibaraki, and Chiba). The survey was a quick report that attempted to grasp an overall trend in 6 prefectures. However, it did not analyze the detailed behavior and conditions in Ibaraki. Like Ibaraki, very few studies focus on Chiba, except for Kawasaki et al. (2012), who focus on Onjuku Town, and Fujimoto et al. (2012) who examine Choshi City through a questionnaire survey.

The primary reasons for the limited number of studies on tsunami evacuation in Ibaraki are that Ibaraki is located more than $300 \mathrm{~km}$ from the epicenter of the main shock, and the tsunami was comparatively lower in height, arrived later, and resulted in a smaller number of casualties than the tsunamis that struck the three Tohoku prefectures. Nevertheless, Ibaraki Prefecture, wherein the greatest seismic intensity 6 upper was observed, still experienced major structural damage. Moreover, 24 deaths and 1 missing person were reported. Of these victims, 16 were aged 60 years or older. Like 
the other prefectures, the elderly comprised a large proportion of the victims. Five people are presumed to have been killed by the tsunami, all of whom were in Kitaibaraki City. To date, the largest historic tsunami in Ibaraki Prefecture, in which 36 people in the Mito fief drowned, was the 1677 Empo Boso-oki Earthquake (Ibaraki Prefecture 2011). In terms of human loss, the Great East Japan Earthquake was the second most damaging earthquake recorded in Ibaraki Prefecture.

Thus, Ibaraki Prefecture decided to conduct an independent questionnaire survey. In cooperation with other research institutes in the prefecture, the authors developed the questionnaire based on their experiences as the secretariat of Ibaraki University's Great East Japan Earthquake Investigation Team (Ibaraki University 2011) from March to September 2011. In addition, the authors had led an investigation on tsunami evacuation. Furthermore, the authors conducted an on-site interview survey to gather in-depth detail of evacuation behavior and evacuation routes in the event of a tsunami. This information could not easily be collected using only the Ibaraki Prefecture questionnaire survey. There is a critical need to focus on survival factors in a disaster, namely the amount of time required for evacuation, mappable information that includes evacuation routes, and awareness of the evacuation. By studying evacuation behavior during this disaster, we aim to help establish local disaster management plans. The interview survey was conducted mainly in Kitaibaraki City and Oarai Town, which were more affected by the tsunami than other areas in the prefecture. In other areas, an overview of tsunami evacuation was obtained from the results of the Ibaraki Prefecture survey (Ibaraki Prefecture 2012a).

For the first time since the Great Hanshin and Awaji Earthquakes in 1995, Ibaraki Prefecture made major amendments to its local disaster management plan in March 2012. Previously, the plan comprised three components: (1) disaster, (2) storm and flood damage, and (3) nuclear power. Following the revision, the "disaster" component was divided into two parts, namely earthquake and tsunami. This new plan formulates a policy for creating a tsunami-resilient community through a combination of strategies, including the construction of seawalls and evacuation buildings, early improvement of evacuation roads and evacuation sites, expansion of tsunami hazard maps to ensure safe evacuation, and the introduction of a text-message service using mobile devices to provide individuals with evacuation information. Ibaraki Prefecture (2012b) updated its anticipated tsunami inundation area, using the worst-case scenario of a Mt9 earthquake occurring offshore of Ibaraki. Furthermore, in conjunction with Ibaraki Prefecture, municipalities are also revising their own disaster management plans. To improve local disaster risk management plans, it is necessary to understand evacuation behavior in its entirety.

The remainder of this study is structured as follows. The second section provides an overview of the questionnaire survey conducted by Ibaraki Prefecture. The third section analyzes the results of the questionnaire survey using data on topographical conditions, and focuses on the amount of time required for people to begin evacuating. In the fourth section, the results of the detailed interview survey of evacuation routes and behavior are revealed. The fifth section examines characteristics and problems in Ibaraki Prefecture based on a comparison with the Tohoku region. Finally, the last section discusses appropriate evacuation behavior and local disaster management plans for the future.

\section{THE IBARAKI PREFECTURE QUESTIONNAIRE SURVEY}

In September 2011, Ibaraki Prefecture, in collaboration with Ibaraki University, the University of Tsukuba, and Tokiwa University, conducted a questionnaire survey on the conditions of the disaster, evacuation, and relief efforts. Questionnaires were distributed to approximately 12,000 people throughout the prefecture. The main reason for this collaboration was to reduce the repetitiveness of the survey for the target audience. Although Ibaraki Prefecture was outside the scope of the investigation by the Central Disaster Prevention Council (2011), there were many requests for an examination of the evacuation procedure by administrative organs, researchers, the mass media, etc. To avoid burdening respondents by asking them similar questions addressed by different people, the collaborative questionnaire survey was initiated after repeated preliminary discussions and coordination between relevant institutions during and after July 2011. 
Table 1 summarizes the questionnaire survey on the Great East Japan Earthquake conducted by Ibaraki Prefecture and other institutions. In Ibaraki Prefecture, the questionnaire survey was distributed to 12,000 people in both coastal and inland areas by dropping them into mailboxes and through the Internet. By the time the interim report was released in October 2011, 3,499 questionnaires had been collected by mail. By March 2012, a final total of 3,890 mail and 754 online surveys had been collected.

Table 2 provides an overview of responses relating to tsunami evacuation in the coastal areas excerpted from the final report on the Ibaraki Prefecture questionnaire survey (Ibaraki Prefecture 2012a). In total, $88 \%$ of respondents experienced the partial or complete collapse of their homes. Evacuation behaviors are divided into three types: immediate, post-response, and urgent evacuation (see Central Disaster Prevention Council 2011). In an immediate evacuation, people began evacuation procedures immediately after the shaking stopped, while in a post-response evacuation, people began to evacuate after taking some kind of action. In the third type, urgent evacuation, people did not immediately evacuate, but waited until seeing the tsunami. Of these three patterns, immediate evacuation has the highest survival rate. The questionnaire survey indicated that $22 \%$ of respondents answered "immediate evacuation," and that most of the others evacuated after taking some kind of action, including locking the house, checking the safety of family members or colleagues, etc. Concrete evacuation routes, actual evacuation situations, and a comparison with other prefectures are discussed later in Section 4.

Table 1 Questionnaire surveys on the Great East Japan Earthquake

\begin{tabular}{|c|c|c|c|}
\hline & Ibaraki Prefecture (2012a) & $\begin{array}{l}\text { Central Disaster } \\
\text { Prevention Council } \\
\text { (2011) }\end{array}$ & MLIT (2013) \\
\hline $\begin{array}{l}\text { Questionn } \\
\text { aire } \\
\text { overview }\end{array}$ & $\begin{array}{l}\text { Ibaraki Prefecture as a whole (conducted from } \\
\text { September to December 2011) } \\
\text { Authors participated from the question } \\
\text { development stage } \\
\text { Understanding the characteristics of the } \\
\text { evacuation based on collected responses }\end{array}$ & $\begin{array}{l}\text { Joint investigation by the } \\
\text { Cabinet Office, the Fire } \\
\text { and Disaster Management } \\
\text { Agency, and the } \\
\text { Meteorological Agency } \\
\text { Survey was conducted in } \\
\text { July } 2011\end{array}$ & $\begin{array}{l}\text { Survey was conducted } \\
\text { from September to } \\
\text { December } 2011\end{array}$ \\
\hline $\begin{array}{l}\text { Investigat } \\
\text { ed areas }\end{array}$ & $\begin{array}{l}<\text { Coastal areas }> \\
\text { Tsunami inundation areas in coastal } \\
\text { municipalities } \\
\text { Anticipated inundation areas and their } \\
\text { neighboring regions } \\
<\text { Inland areas }> \\
\text { Areas around major evacuation facilities in } \\
\text { municipalities except for the abovementioned } \\
\text { areas of Ibaraki Prefecture }\end{array}$ & $\begin{array}{l}\text { Iwate Prefecture: } 391 \\
\text { people } \\
\text { Miyagi Prefecture: } 385 \\
\text { people } \\
\text { Fukushima Prefecture: } 94 \\
\text { people }\end{array}$ & $\begin{array}{l}\text { About } 5,000 \text { respondents } \\
\text { from } 62 \text { municipalities in } \\
6 \text { prefectures (Aomori, } \\
\text { Iwate, Miyagi, } \\
\text { Fukushima, Ibaraki, and } \\
\text { Chiba) }\end{array}$ \\
\hline Methods & $\begin{array}{l}<\text { Distribution }> \\
\text { Dropping questionnaires into mailboxes in target } \\
\text { areas and an online survey } \\
\text { 1) Mail: } 12,000 \text { ( } 9,880 \text { in inland areas and } 2,120 \\
\text { in coastal areas) } \\
\text { 2) Internet questionnaire } \\
<\text { Collection> } \\
\text { 1) By interim report in October } 2011: 3,499 \text { by } \\
\text { mail ( } 819 \text { valid responses from coastal areas) } \\
\text { 2) By final report in March } 2012: 3,890 \text { by mail } \\
\text { (collection rate: } 32.4 \% \text { ) and } 754 \text { Internet } \\
\text { responses ( } 955 \text { valid responses from coastal } \\
\text { areas) }\end{array}$ & $\begin{array}{l}\text { Interviews at temporary } \\
\text { housing and evacuation } \\
\text { centers }\end{array}$ & $\begin{array}{l}\text { First report focuses on } \\
\text { damage to infrastructure } \\
\text { and buildings. The second } \\
\text { addresses inundation and } \\
\text { human damage, while the } \\
\text { third looks at evacuation. } \\
\text { In the third report, } \\
\text { interviews were } \\
\text { conducted at temporary } \\
\text { housing and evacuation } \\
\text { centers. } \\
10,603 \text { valid responses in } \\
\text { total were received, } 364 \\
\text { in Ibaraki }\end{array}$ \\
\hline
\end{tabular}


Table 2 Overview of survey results on evacuation in the coastal areas of Ibaraki

\begin{tabular}{|c|c|}
\hline Question & Answer \\
\hline Respondents & $\begin{array}{l}955 \text { responses } \\
69 \% \text { of respondents were in their } 50 \text { s or older, } 16 \% \text { in their } 40 \text { s, and } 12 \% \text { in their } \\
30 \mathrm{~s}\end{array}$ \\
\hline Extent of damage to home & Partial collapse: $65 \%$; complete or half collapse: $23 \%$ \\
\hline $\begin{array}{l}\text { Were respondents aware of tsunami } \\
\text { evacuation sites? }\end{array}$ & $54 \%(46 \%$ were not aware $)$ \\
\hline $\begin{array}{l}\text { Were respondents aware of hazard } \\
\text { maps and anticipated inundation } \\
\text { areas? }\end{array}$ & $30 \%(70 \%$ were not aware $)$ \\
\hline Did respondents evacuate? & $59 \%$ evacuated from the tsunami \\
\hline $\begin{array}{l}\text { Starting time of evacuation (time } \\
\text { required to start evacuating } \\
\text { measured from the earthquake) }\end{array}$ & $<5 \min : 25 \%$; 5-15 min: $17 \%$; $15-30 \min : 34 \% ; 30-60 \min : 16 \%$ \\
\hline $\begin{array}{l}\text { Behavior just before evacuating } \\
\text { (multiple responses) }\end{array}$ & $\begin{array}{l}\text { Immediate evacuation: } 22 \% \text {; post-response evacuation (preparations: } 32 \% \text {; locking } \\
\text { up: } 28 \% \text {; safety check of family members/colleagues: } 26 \% \text {; returning home: } 26 \% \text {, } \\
\text { etc.), and urgent evacuation (watched Tsunami: } 12 \% \text { ) }\end{array}$ \\
\hline $\begin{array}{l}\text { Awareness of the possibility of } \\
\text { tsunami arrival }\end{array}$ & $\begin{array}{l}\text { Thought that a large tsunami was a possibility: } 14 \% \text {, did not think a tsunami was a } \\
\text { possibility: } 86 \% \text { (were not concerned about a tsunami: } 34 \% \text {; did not think a tsunami } \\
\text { would come: } 10 \% \text {; thought a tsunami would come but that it would not be big: } \\
41 \% \text { ) }\end{array}$ \\
\hline Evacuation method & Car: $66 \%$; walk (run): $28 \%$ \\
\hline Evacuation destination & High ground: $38 \%$; school, hospital, community center, etc.: $32 \%$ \\
\hline
\end{tabular}

\section{ANALYSIS OF THE STARTING TIME OF EVACUATION}

We analyzed in detail the locations of the residents of the coastal areas when the earthquake occurred, the starting time of evacuation, and evacuation routes by combining the results of the questionnaire survey conducted by Ibaraki Prefecture with topographical and map data obtained from the Geographic Information System (GIS). Based on this analysis, issues relevant to the evacuation were identified.

The final report on the questionnaires (March 2012) included 955 responses from coastal areas. Of these, 870 respondents roughly identified their own home from their zip code, and 361 of the 870 responded that they were in their own homes when the earthquake occurred. Of these 361 respondents, the 235 who answered that they had evacuated were analyzed. Respondents not present at their own homes when the earthquake occurred were excluded from the analysis because data about their locations could not be obtained from the questionnaire survey. Additional data were examined to obtain the results of the questionnaire analysis. These data contained topographical and map data, including the locations of evacuation centers opened by Ibaraki Prefecture, anticipated inundation areas identified by Ibaraki Prefecture (2007), hazard maps developed and distributed by municipalities based on anticipated inundation areas, areas actually inundated in this tsunami (Geospatial Information Authority of Japan 2011), and geographic information such as elevation. Background maps were based on national base maps $(1: 25,000)$ and digital national land information.

\subsection{Starting time of evacuation by municipality}

Fig. 1 shows the starting time of evacuation of the 235 respondents who had evacuated. These 235 respondents were of the 361 who answered that they were in their homes in the coastal areas when the earthquake occurred. The size of the circle in the figure corresponds to the number of respondents in 
the municipality, and the values in parentheses after the names of the municipalities are averages of the evacuation starting time. As indicated by the results of the questionnaire survey discussed in the previous section, $59 \%$ of coastal area residents evacuated in total, while $76 \%$ of them had evacuated within 30 minutes. However, this varied extensively between municipalities. As shown in Fig. 1, the starting time of evacuation for respondents in their own homes when the earthquake occurred ranged from within ten minutes to over one hour.

It is necessary to understand the limitation on the time at which the tsunami arrived. At that time in Ibaraki Prefecture, only one tsunami observation facility was within the jurisdiction of the Meteorological Agency. As there were no official records of the arrival time and height of tsunamis in other areas, these are estimated based on photographs and eyewitness information. Although there was some variation according to area, the first wave of the tsunami arrived at Ibaraki Prefecture about 30 minutes after the earthquake (14:46), and the second wave, which caused serious damage, arrived about 45 minutes after the earthquake. For example, a first wave of $1.7 \mathrm{~m}$ arrived at 15:17 and a second wave of $3.9 \mathrm{~m}$ arrived at 15:43 at the coast of Oarai Town (Meteorological Agency 2011). According to eyewitnesses, the coast of Kitaibaraki City was hit by a first wave of $0.5 \mathrm{~m}$ at 15:23 and a second wave of 4-5 $\mathrm{m}$ at around 15:31 (see Kitaibaraki Shinsaiki Henshu Iinkai 2012). In Ibaraki Prefecture's coastal areas, many residents evacuated immediately after the arrival of the second wave, which was higher than the first wave. However, witnesses noted that the third and subsequent waves, which arrived after the evacuation was almost complete, were the highest. It is important to remember that the first tsunami wave is not necessarily the highest.

Generally, public facilities such as elementary schools are designated as evacuation centers. Figs. 2, 3 , and 4 illustrate the starting time of evacuation, inundated area, and elevation of elementary school districts in the municipalities. They demonstrate that many residents in the following school districts took longer than 30 minutes to evacuate. These include Otsu Elementary School District and Sekinami Elementary School District in Kitaibaraki City, Nakamaru Elementary School District in Tokai Town, Hiraiso Elementary School District in Hitachinaka City, Iwaimachi Elementary School District and Ohnuki Elementary School District in Oarai Town, Takamatsu Elementary School District in Kashima City, and Yanagawa Elementary School District and Hasaki West Elementary School District in Kamisu City. 


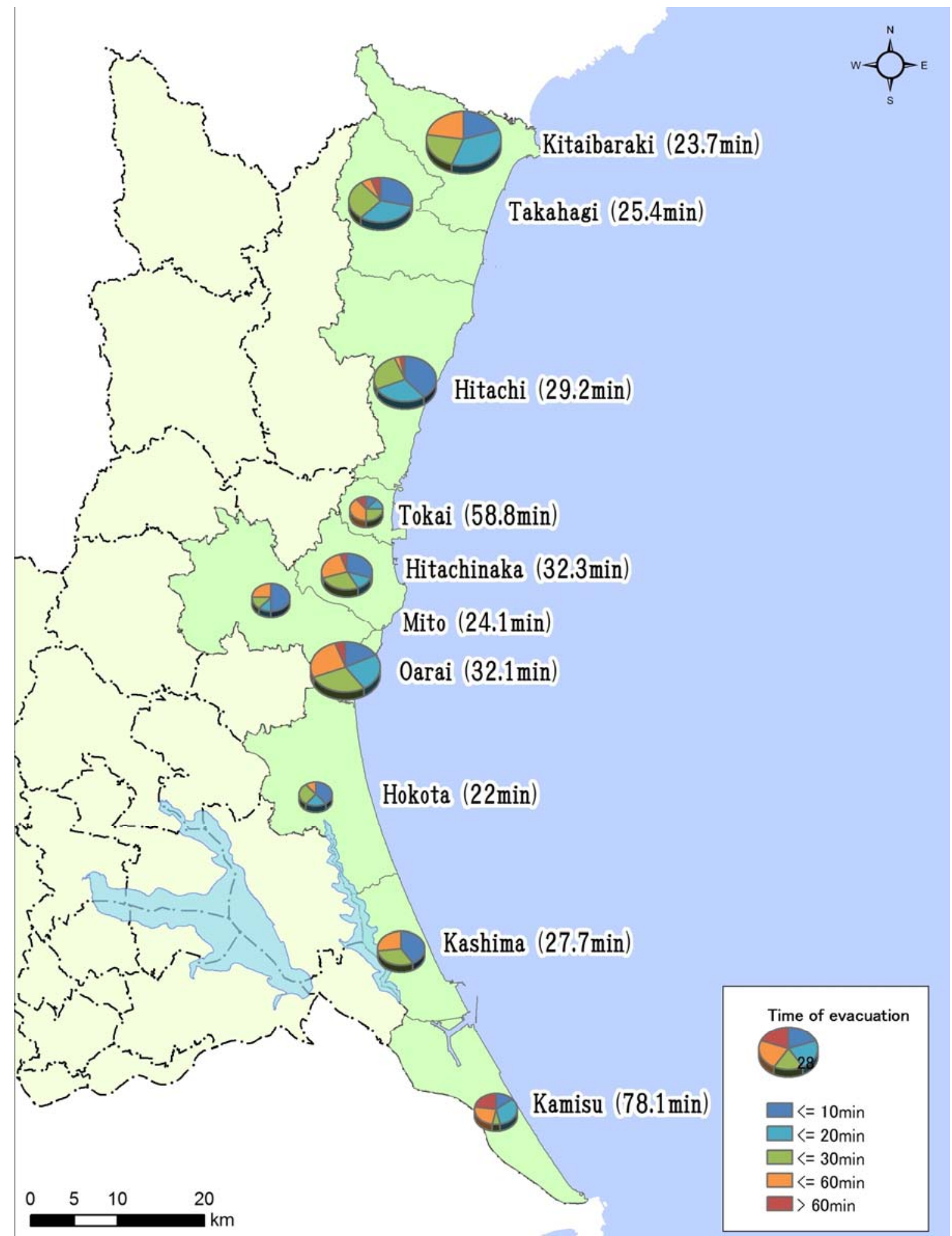

Fig. 1 Starting time of evacuation by municipality (evacuation from own homes) 


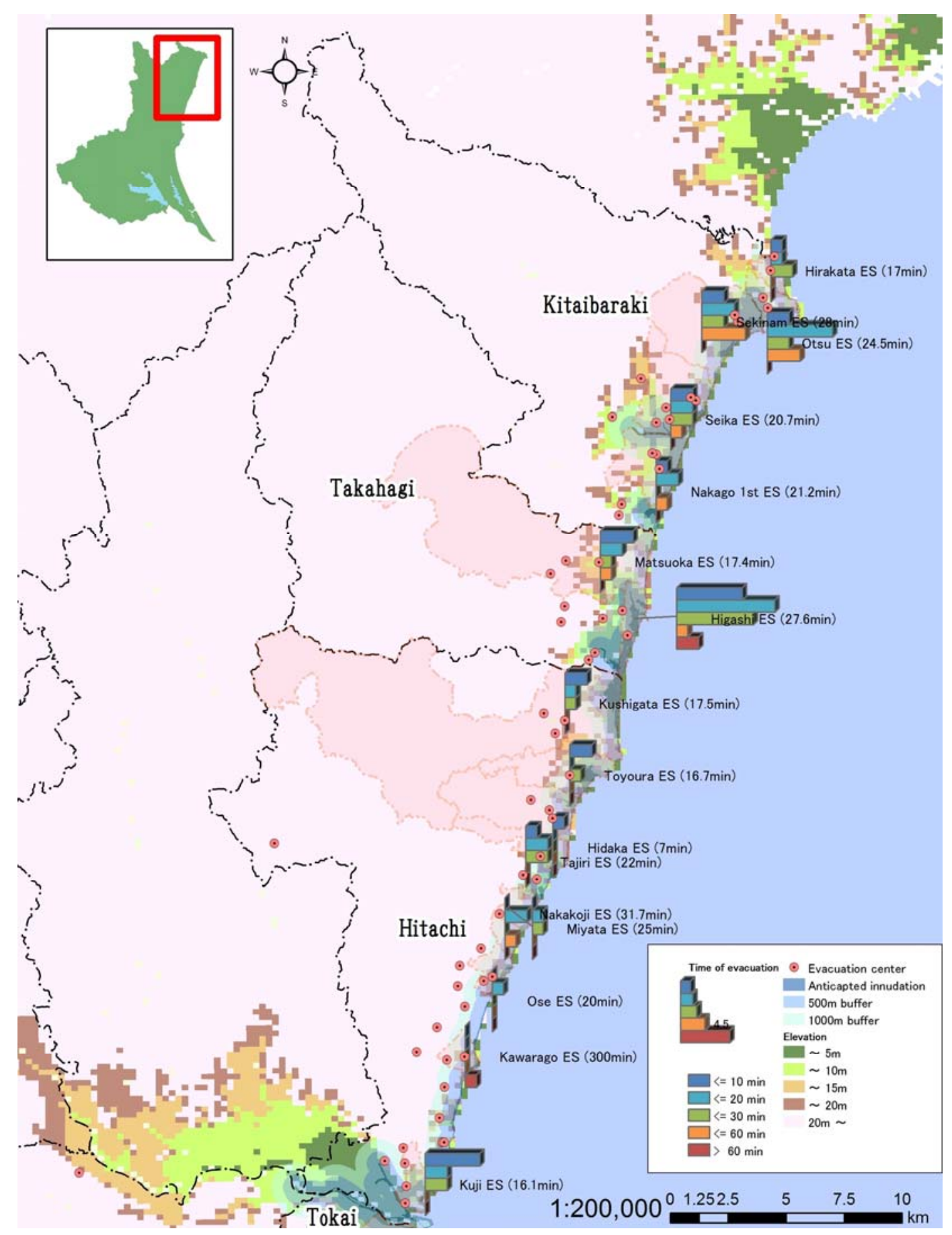

Fig. 2 Starting time of evacuation, inundated areas, and elevation in the northern region 


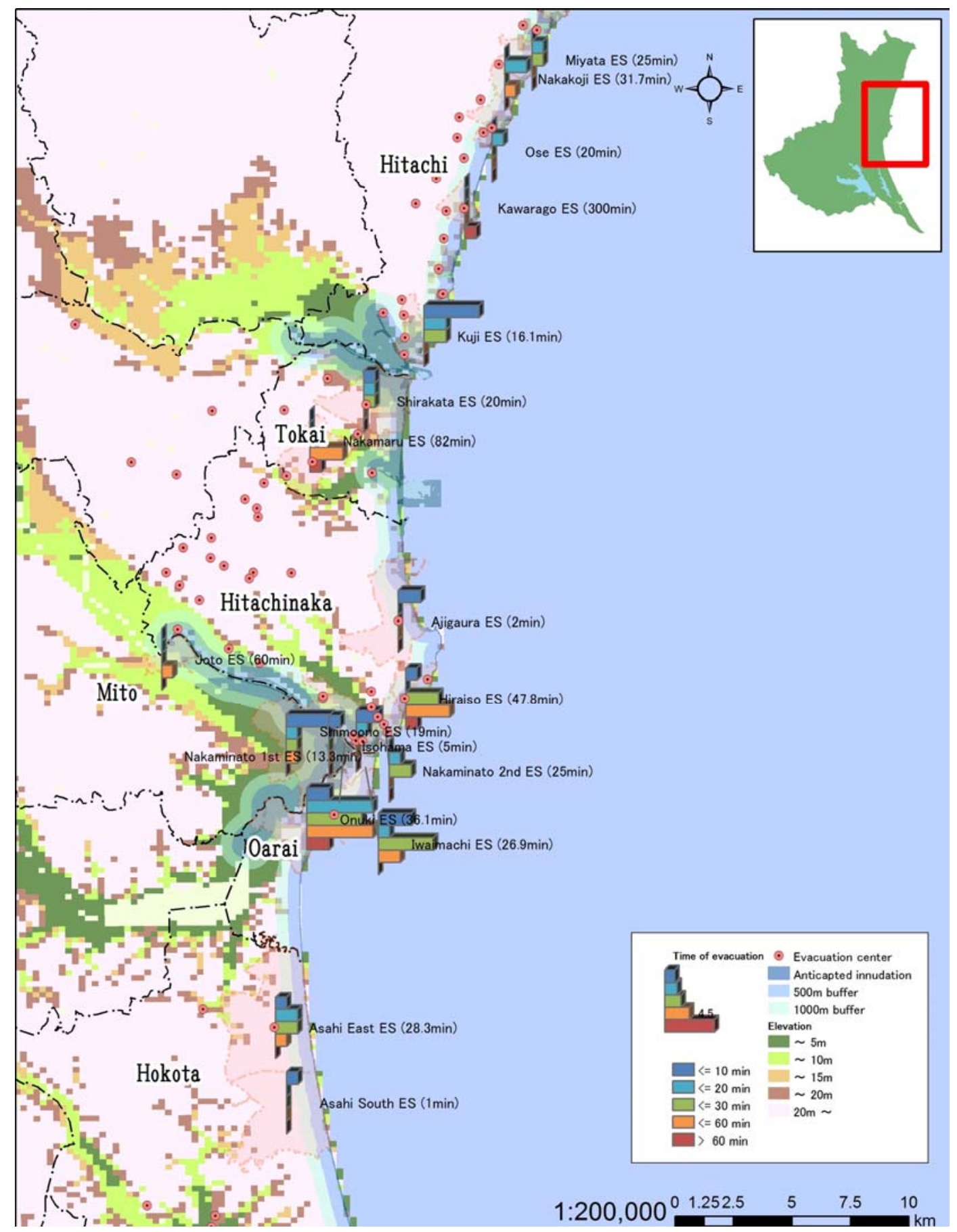

Fig. 3 Starting time of evacuation, inundated areas, and elevation in the northern, central region 


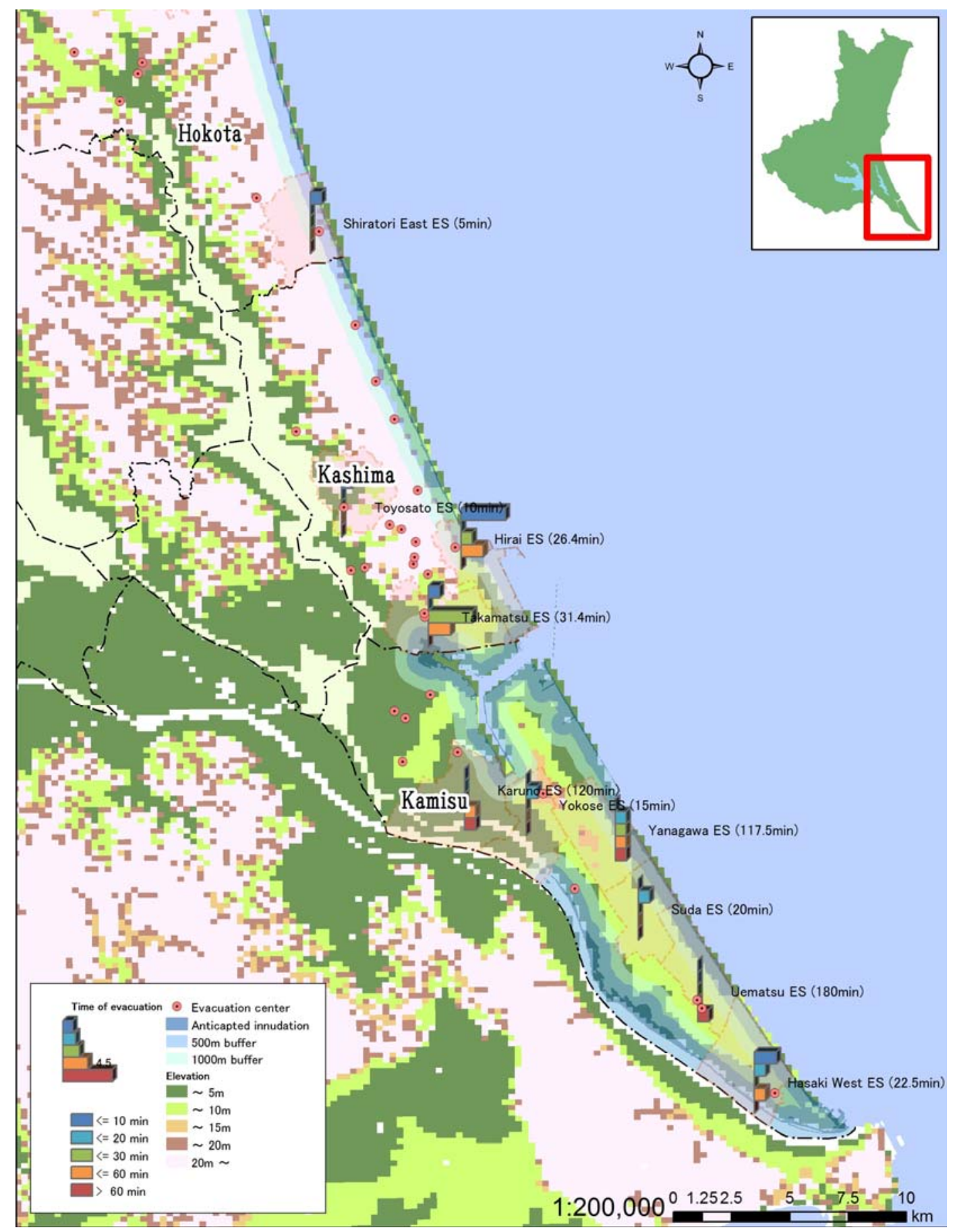

Fig. 4 Starting time of evacuation, inundated areas, and elevation in the Rokko region

\subsection{Starting time of evacuation and topographical conditions}

As shown in Figs. 1 to 4, the starting time of evacuation varied by area. The causes of this variation are thought to include whether residents were familiar with the anticipated inundation areas (hazard maps) prepared by Ibaraki Prefecture (2007), whether residents expected the tsunami to arrive, and the distance from an anticipated inundation area to the respondent's location when the earthquake occurred. Accordingly, the starting time of evacuation and topographical conditions of the 235 respondents who evacuated from their own homes when the earthquake occurred were analyzed 
statistically.

The results indicate no correlation between the starting time of evacuation and the three distance factors, that is, the distance to an evacuation center, the elevation of the respondent's location when the earthquake occurred, and the distance from areas actually inundated (Geospatial Information Authority of Japan 2011). In contrast, analysis of the relationship between the distance from anticipated inundation areas (hazard maps) and the starting time of evacuation showed that, of those respondents who answered that the distance was within $500 \mathrm{~m}$, the number of respondents who started to evacuate within 20 minutes was slightly higher (Fig. 5). However, when one's residence is set back from the anticipated inundation area by more than $500 \mathrm{~m}$, no differences are evident with regard to the starting time of evacuation. When one's home is inside the anticipated inundation area, they are highly concerned, but once their home is located away from the area, this concern decreases dramatically. This result concurs with the questionnaire conducted by Tanaka et al. (2006), who surveyed the 2004 Tsunami at Aichi Prefecture, Japan. In Aichi's case, although people living within $100 \mathrm{~m}$ of the area thought it was possible that the "earthquake could trigger a tsunami," those living away from the area did not think in those terms. This trend, namely that the "recognition of certain dangers is high at the fringe of the area, but markedly decreases several meters back," should be applied not only to tsunamis but also to other natural hazards.

It was found that among the topographical conditions, the distance from anticipated inundation areas had the strongest correlation to the starting time of the evacuation. The Ibaraki Prefecture questionnaire survey revealed that only $30 \%$ of respondents were aware of anticipated inundation areas, and furthermore, some respondents who were aware had stayed home rather than evacuate the area. This suggests that multiple factors influence evacuation behavior, as discussed in Sections 3.3 and 4. Section 3.3 examines the influence of other dynamics on evacuation behavior.

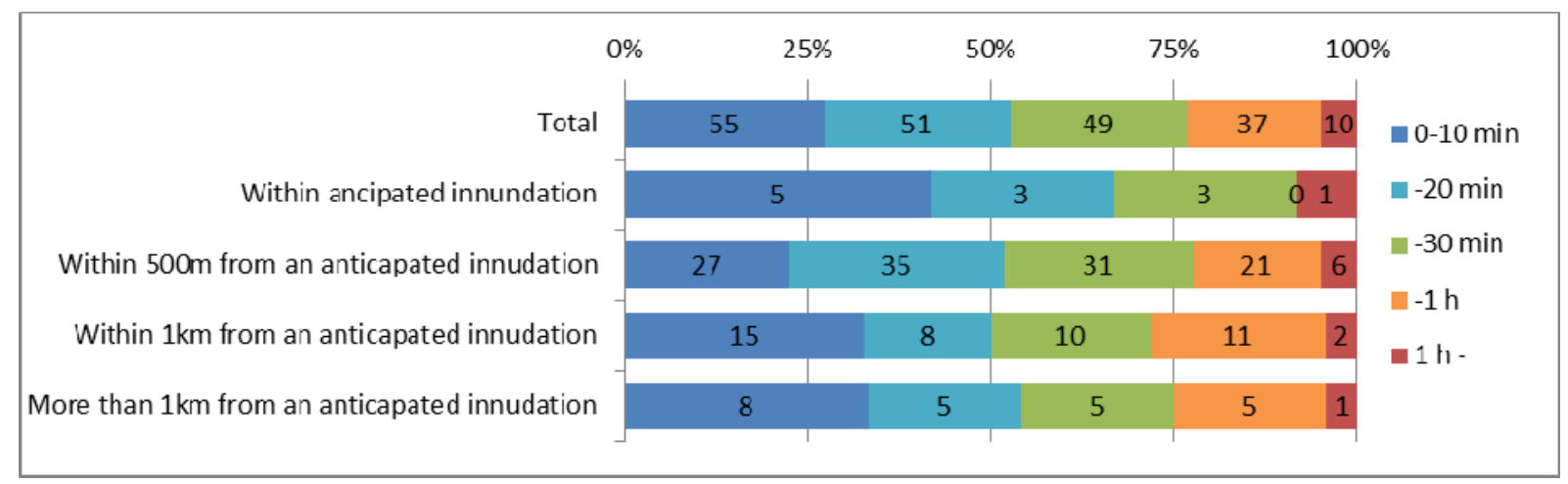

Fig. 5 Relationship between the distance from anticipated inundation areas (hazard maps) and the starting time of evacuation

\subsection{Factors influencing the starting time of evacuation}

To identify factors other than topographical conditions that affect the starting time of evacuation, the influence of each factor was analyzed by using quantification theory type I (Table 3). Quantification theory type I is a method for quantifying qualitative data and conducting multiple regression analysis (see Hayashi 1953). Hayakawa and Imamura (2002) determined that the experience of a tsunami and the intensity of an earthquake had a greater effect on the starting time of evacuation than other factors such as location and time zone. They applied quantification theory type I to evacuation cases in Japan (1993 Earthquake off the Southwest coast of Hokkaido and 1994 Earthquake off the East coast of Hokkaido). They also developed a model to estimate the starting time of evacuation in Miyagi Prefecture according to timing, for example the time of the earthquake and when warnings are issued. As Ibaraki recorded no deaths in the 1960 Chile Tsunami and has very few residents who have experienced a tsunami, this section focuses on residents' awareness of evacuation centers, hazard maps, 
and warnings rather than on tsunami experiences.

Herein, 197 answers from respondents whose locations were unknown at the time of the earthquake were analyzed in addition to the responses from the 235 respondents who evacuated from their own homes when the tsunami occurred (i.e., 432 responses in total). Focusing on item ranges, Question 9: "Awareness of evacuation warnings (whether or not respondents heard or saw evacuation warnings issued by the Meteorological Agency)" was found to be the first factor. However, there were almost no differences between cases where respondents heard evacuation warnings before or after the start of evacuation (35.9 and 37.8 minutes) and cases where they did not. It is also notable that the starting time of evacuation of respondents who did not evacuate in spite of being aware of evacuation warnings - those who ignored the warnings - varied greatly (more than 60 minutes). The reasons they did not evacuate were analyzed in detail by focusing on differences in (1) age, (2) type of home, and (3) circumstances of family members living together. As a result, while there was little difference in the starting time of evacuation between factors (1) and (2), factor (3) affected the starting time of evacuation, because the elderly comprised a large proportion of those who heard evacuation warnings but did not evacuate. With regard to family members living together in (3), of the 163 respondents who answered "1. (Heard the warning) before evacuation (and started evacuating)," 43 people (26\%) live with elderly family members, while $6(37 \%)$ among 16 respondents answered " 4 . Heard the warning but did not evacuate." It may be that these respondents had to go back home to help elderly family members even though they recognized the alert or took a long time to help them evacuate. MLIT (2013) also illustrated that 39\% of respondents searched for their families and colleagues soon after the earthquake (14:46-50), and $12 \%$ did so even after 30 minutes (15:15-20). Ibaraki may display similar tendencies.

The second factor was Question 2: "Awareness of hazard maps and anticipated inundation areas (whether they had been aware of hazard maps and the anticipated tsunami inundation areas map prepared by Ibaraki Prefecture before the disaster)." Respondents who answered that they "had known about both" started evacuating 32.2 minutes, on average, after the earthquake. Although the inundation areas shown in the anticipated inundation areas prepared by Ibaraki Prefecture (2007) and the hazard maps developed by municipalities based on anticipated inundation areas were essentially the same, awareness of these by residents differed because they were distributed in different ways at different times. According to Ibaraki Prefecture (2012a), eight of ten coastal municipalities developed and distributed hazard maps before the earthquake. As shown in Table 3, the starting time of evacuation of respondents who answered that they "were only aware of Ibaraki Prefecture's anticipated inundation areas map" was 50.7 minutes on average, whereas respondents who answered that they "were not aware of either" was 35.5 minutes on average. This suggests that an awareness of the anticipated inundation areas does not necessarily have a favorable effect. It is possible that respondents who had known about both maps evacuated early because they have always been concerned about tsunami risks, but respondents who had known only about the anticipated inundation areas held the misconception that the tsunami would not arrive, and thus, they did not have to evacuate because their homes were located outside anticipated inundation areas.

The third factor was the distance from anticipated inundation areas described in Section 3.2. Although there was some variation among individuals, residents who lived closer to anticipated inundation areas tended to evacuate earlier. The fourth factor was Question 6: "Awareness of the possibility of tsunami arrival (whether they thought a tsunami would strike when the earthquake occurred)." A large difference between the response, "Was not concerned about a tsunami" and others is evident. The fifth factor was Question 1: "Awareness of evacuation sites." Those aware of evacuation sites evacuated earlier (32.7 minutes on average). 
Table 3 Factors influencing the starting time of evacuation analyzed by quantification theory type I

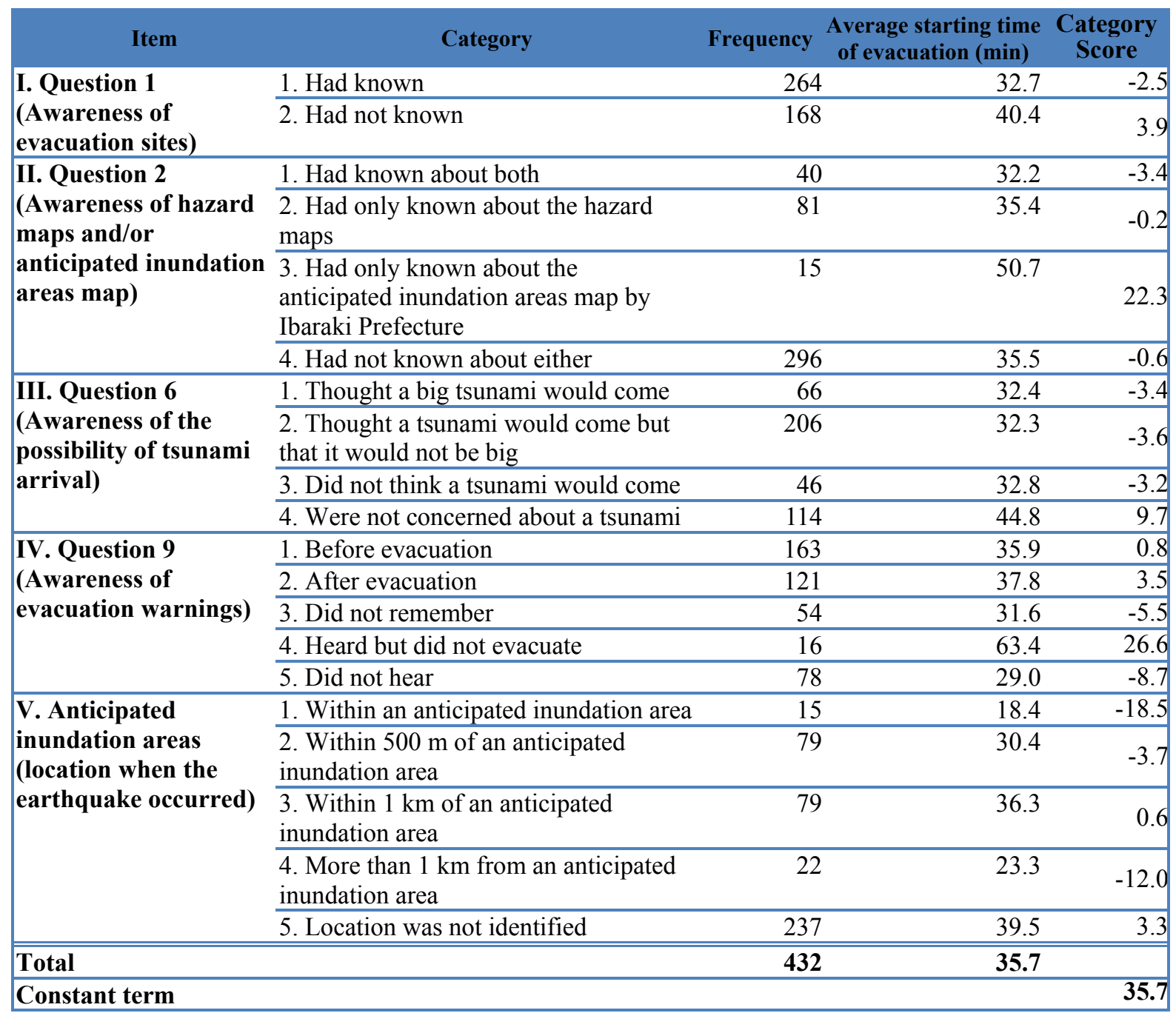

Note:

1) The total frequency number of 432 is more than the 235 responses originally analyzed because responses from respondents whose location at the time of the earthquake was not identified were added to the analysis.

2) Responses in which Question 9 was not answered were counted as "3. Did not remember."

3) A response having an outlier in the starting time of evacuation was excluded from analysis. 


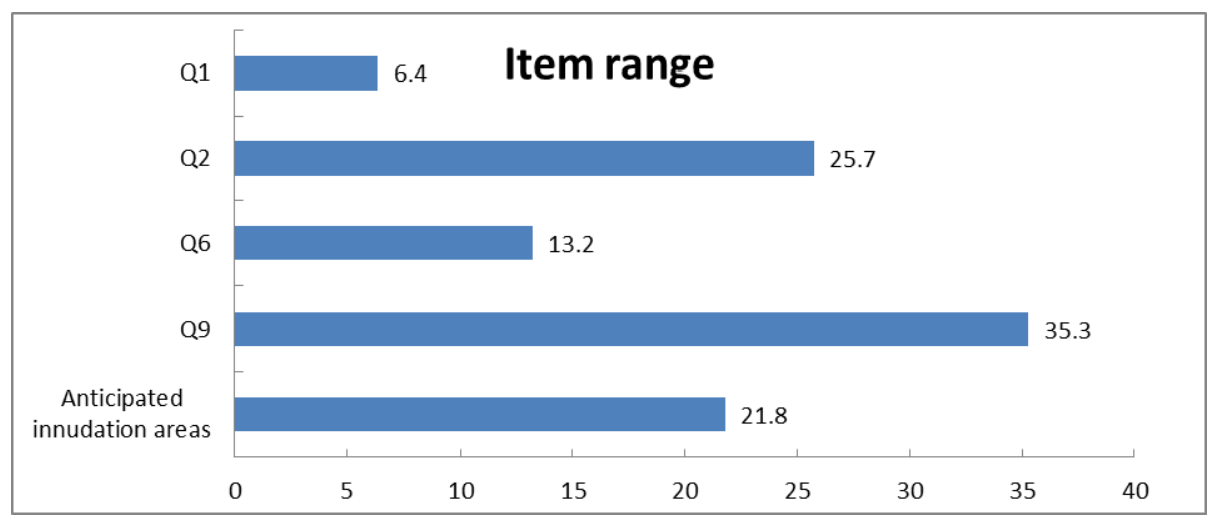

\section{ANALYSIS OF EVACUATION ROUTES BASED ON THE INTERVIEW SURVEY}

In addition to the statistical analysis of the starting time of evacuation with respect to topographical conditions and awareness as described in Section 3, we conducted an interview survey on respondent location at the time the earthquake occurred, the starting time of evacuation, and evacuation routes in Kitaibaraki City and Oarai Town. We wrote a prompt report based on a simple interview survey in Oarai Town during March and April 2011 (Ito et al. 2011), but were unable to ask about a detailed evacuation route at the time. We conducted a detailed interview survey on evacuation routes in Kitaibaraki City afterwards, from August 25-27 (10 people from Isohara district), on December 4 and 17 (3 people from Isohara and 1 from Ohtsu district), and in Oarai Town on September 14 (4 people). As a courtesy to the interviewees, due consideration was taken to not repeat questions already asked in the questionnaire survey. For the interview survey, the authors asked interviewees to describe their evacuation routes and circumstances in detail using maps, which took about one hour per person.

Figs. 6 and 7 show sample answers from residents of Kitaibaraki City and Oarai Town respectively on evacuation routes. Both the anticipated inundation areas identified by Ibaraki Prefecture (2007) and the areas actually inundated (Geospatial Information Authority of Japan 2011) are indicated in color on the maps. Despite living near areas actually inundated, many residents did not evacuate immediately. Rather, they evacuated only after taking some kind of action, for example, going back to their homes or workplaces, checking the safety of families or colleagues, and then evacuating, narrowly escaping danger. Much like responses to the questionnaire survey, most interviewees responded that they eventually evacuated by car to a designated evacuation center or fled to higher ground. Of 14 interviewees in Kitaibaraki City, there was 1 immediate, 7 post-response, and 1 urgent evacuation. Five interviewees did not evacuate. Of four respondents in Oarai Town, there was one immediate and three post-response evacuations. Similar to the Ibaraki Prefecture questionnaire survey, which indicates that $66 \%$ of residents evacuated by car, most evacuated by car ( 8 of 14 respondents in Kitaibaraki City, and 3 of 4 in Oarai Town), fleeing to designated evacuation centers or higher ground.

The questionnaire and interview surveys revealed that there were few residents in Ibaraki Prefecture who imagined the tsunami (14\% in the Ibaraki Prefecture survey, 5 of 14 in Kitaibaraki, and 2 of 4 in Oarai), and that many residents underestimated the tsunami based on their experiences of the 2010 Chile Earthquake and other previous earthquakes. Some elderly residents underestimated the extent of damage a possible tsunami would cause. This was based on their previous experience of the tsunami following the 1960 Chile Earthquake, which caused inundation damage but did not reach their location at the time ( 3 of 4 interviewees responded as such in Kitaibaraki and Oarai). This is considered a "normalcy bias" (see Hirose 1984; Yamori 2009; Katada 2011), which functions to maintain a mental state when people face disaster. It causes people to underestimate both the occurrence of a disaster and its possible effects. It also results in the loss of capacity for people to cope with a disaster once it occurs. Similar cases were reported in Kamaishi City during the Miyagiken-Oki Earthquake in 2003 (Katada et al. 2005) and in the Choshi City earthquake in 2011 (Fujimoto et al. 2012). However, some residents and fishermen in Oarai Town, who recalled the 1960 Chile 
Earthquake, evacuated or launched their boats into the offing (Ito et al. 2011). Thus, reactions varied according to individual experiences and judgment.

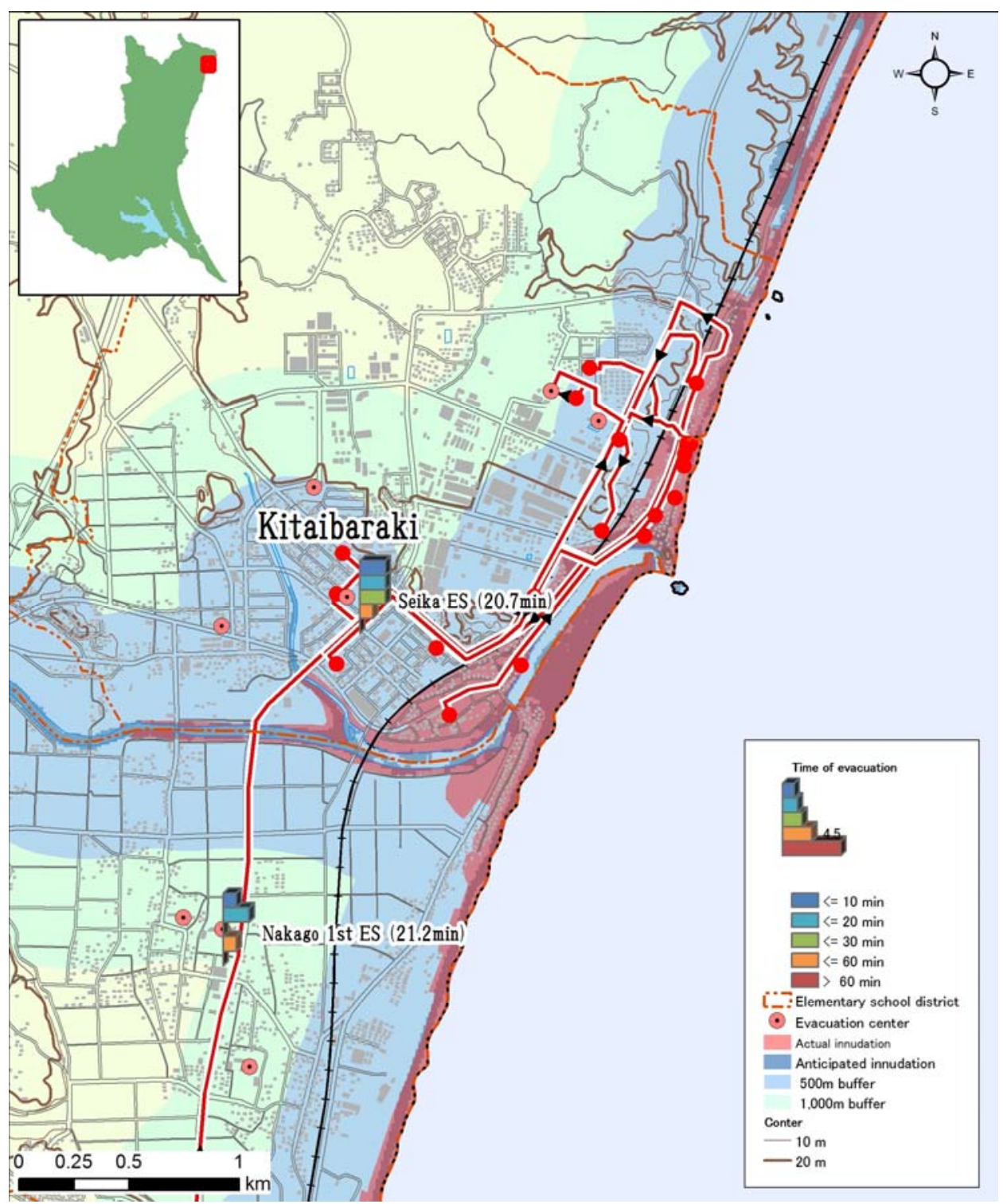

Fig. 6 Inundated areas and evacuation routes of residents in Kitaibaraki City 


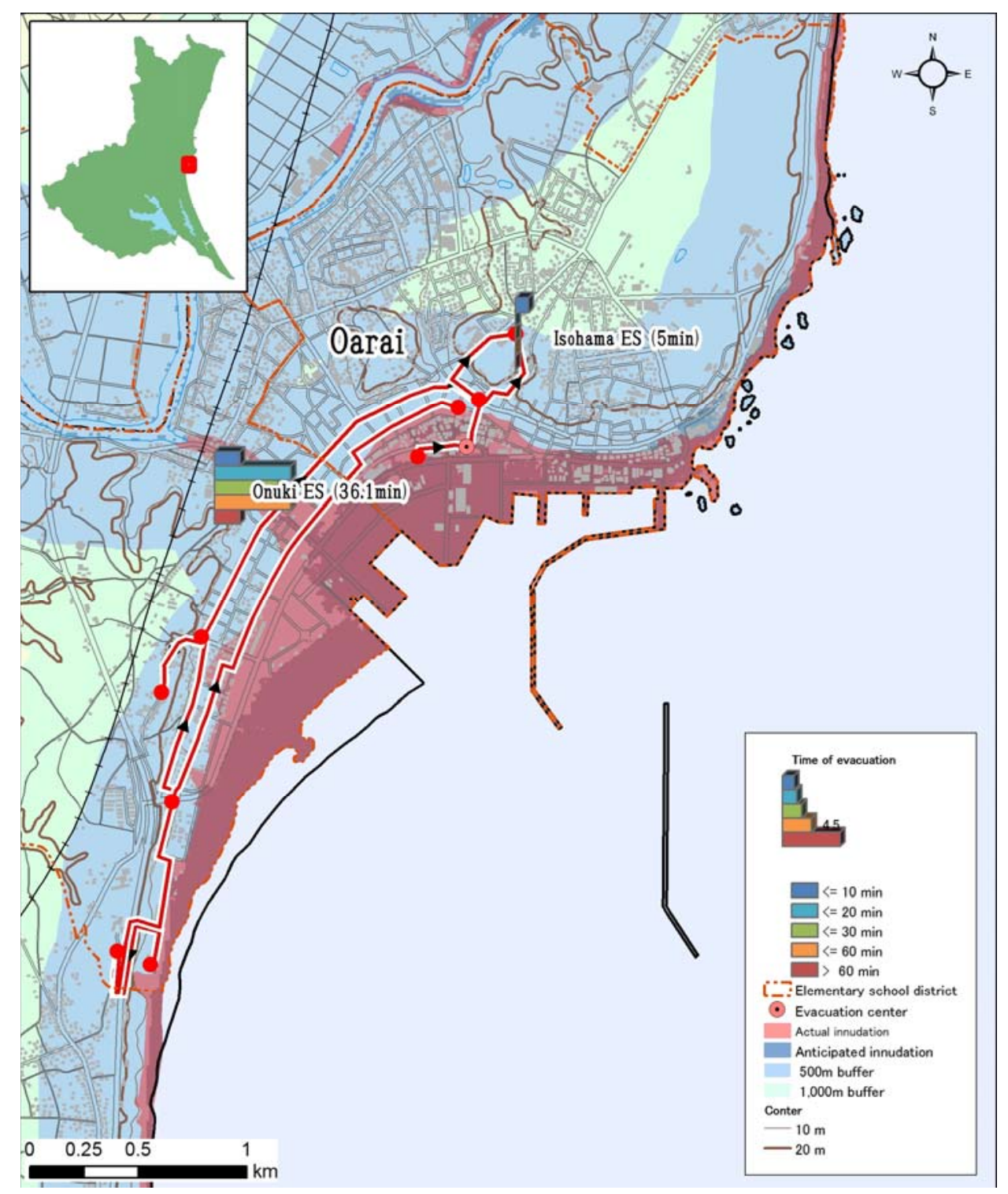

Fig. 7 Inundated areas and evacuation routes of residents in Oarai Town

\section{LESSONS LEARNED FROM THE DISASTER}

This section compares the results of Ibaraki Prefecture's evacuation survey to that of the three Tohoku prefectures, and discusses the lessons learned from this disaster. The Ibaraki Prefecture survey (Ibaraki Prefecture 2012a) demonstrated that only $22 \%$ of residents evacuated immediately, and that many evacuated after taking some kind of action. The interview survey revealed similar tendencies. On the other hand, according to the Central Disaster Prevention Council (2011), 57\% of residents in the three Tohoku prefectures evacuated immediately, while $31 \%$ evacuated after taking some kind of action. Furthermore, a wide-area investigation from Aomori Prefecture to Chiba Prefecture by the MLIT (2013) demonstrated that about $40 \%$ of residents began evacuating within 10 minutes, although it did not distinguish between immediate and post-response evacuation. In contrast to the three Tohoku prefectures that experienced the 1896 Meiji Sanriku Earthquake, the 1933 Showa Sanriku Earthquake, and others, Ibaraki Prefecture had not experienced substantial tsunami damage in recent years. This suggests that public awareness of the tsunami threat was lower in Ibaraki.

The subjects of these surveys were survivors. On the other hand, an online survey by Weathernews 
Inc. (2011) concerning differences in evacuation behavior between survivors and victims revealed that the average starting time of evacuation for survivors was 19 minutes, whereas that of victims was 21 minutes. Furthermore, $20 \%$ of victims did not evacuate at all.

Needless to say, the primary purpose of tsunami evacuation is to reduce the loss of human life as much as possible. Katada (2011), who has advised disaster management education in Kamaishi City for many years, proposed three principles for tsunami evacuation. Checking tsunami evacuation in Ibaraki Prefecture against these three principles reveals both successes and issues needing consideration.

(1) "Don't believe in preconceived ideas": The Ibaraki Prefecture questionnaire survey revealed that only about $30 \%$ of respondents were aware of anticipated inundation areas and hazard maps, and that some respondents who were aware chose to stay home rather than evacuate based on preconceived notions. It should be noted that the hazard map shows only simulations, not the reality. As shown in Sections 3 and 4, some areas experience greater tsunami inundation than expected, even in Ibaraki after this earthquake. Thus, it is necessary to think about larger hazards for any situation.

(2) "Do everything you can": Some evacuation centers in Oarai Town were inundated (Fig. 7). Fortunately, no one in Oarai Town was killed by the tsunami. This success was achieved as a result of: 1) strenuous calls for evacuation by the local government and fire companies using the community wireless system for disaster alerts, 2) distribution of hazard maps and cooperation among neighbors, 3) disaster drills at and guidance by schools and kindergartens, and 4) moving designated evacuation centers to higher ground (Ito et al. 2011; Inoue 2011). Indeed, the safety of designated evacuation centers is not always assured. Ten municipalities along the coast in Ibaraki are currently revising their local disaster management plans and rechecking the locations of evacuation centers according to the situation after the earthquake.

(3) "Take leadership in evacuating": Many residents evacuated after taking some kind of action, such as searching for family members, going back home, checking the safety of relatives or colleagues, etc. Because such post-response evacuation endangers their lives if a tsunami strikes earlier than expected, this action should be discouraged despite peoples' reluctance to carry out the safety check later. Even though most people think they need to evacuate, they cannot act without a "trigger"- for example, someone's cry for help. If there were a "trigger," people could evacuate faster. Thus, people who have influence on those around them should lead the evacuation.

These three principles were not generally instituted before the disaster. To lower the loss of life caused by tsunamis, these important principles should be widely instilled. On the other hand, in many cases residents did not evacuate immediately (post-response evacuation) because they wanted to help children and bedridden or disabled family members (in the Ibaraki Prefecture survey, $26 \%$ checked their safety and 26\% returned home). Measures for such cases have to be considered in each community. In addition, the number of residents who can evacuate only by car will increase in a graying society. It will be necessary to construct and maintain evacuation friendly roads and establish rules for motor vehicle evacuation. The Central Disaster Prevention Council (2011) changed the means of tsunami evacuation from "prohibition of the use of cars in principle" to "on foot in principle." If people have no choice but to evacuate by car, means of evacuation have to be sufficiently discussed based on various circumstances such as distance from evacuation sites, vulnerable people who require support in a disaster situation, evacuation routes, etc., to ensure a secure and successful evacuation.

\section{CONCLUSIONS}

This study examined the actual conditions of tsunami evacuation in Ibaraki Prefecture based on questionnaire and interview surveys, as well as geographic information. According to the Ibaraki Prefecture survey, only $14 \%$ of those who considered the likelihood of a tsunami evacuated, while many residents evacuated only after taking some kind of action. We analyzed the dependency of the starting time of evacuation on several factors, including awareness of evacuation warnings, 
understanding of anticipated tsunami inundation areas and hazard maps, and distance from anticipated inundation areas. We found that those who were aware of evacuation sites, hazard maps and/or anticipated inundation areas maps, and who lived in inundated areas tended to evacuate earlier. The primary reasons for post-response evacuation were preparation, locking up, and a safety check. However, only a few residents were aware of the anticipated inundation areas and hazard maps. Consequently, some residents stayed at their location rather than evacuate because of preconceived ideas. The starting time of evacuation highly depended on individual judgment and family conditions. The fact that only $14 \%$ of respondents considered the possibility of a tsunami implies that Ibaraki was generally recognized as a low risk prefecture for tsunamis, even after the 1960 Chile Earthquake.

For the first time since the 1995 Great Hanshin and Awaji Earthquakes, Ibaraki Prefecture made major amendments to its local disaster management plan in March 2012, adding an independent section on tsunami hazards. This study suggests that individual awareness and judgment are more critical than public support and cooperative assistance such as alerts by local municipalities or communities, especially for urgent evacuation. To effectively implement local disaster management, it is essential to raise awareness of or take leadership during evacuation, that is, self-assistance. After the new anticipated inundation simulation of Ibaraki Prefecture (2012b), some primary/secondary students and local residents are measuring the evacuation route for themselves, rather than relying on the government. Such good practices will be a great help.

The damage caused by the 2011 Tsunami in Ibaraki Prefecture was relatively minor, as the earthquake epicenter was much farther from Ibaraki Prefecture than from the Tohoku region. However, aftershocks continue and the potential for the reoccurrence of tsunamis of a similar or larger magnitude cannot be ignored. To minimize future damage, evacuation behaviors and local disaster management plans must be reconsidered based on the successes identified and lessons learned from this disaster.

\section{ACKNOWLEDGMENT}

The earlier Japanese version of this study was presented to the Journal of Japan Association for Earthquake Engineering. This study was based on the results of a questionnaire survey conducted in Ibaraki Prefecture, and the results of an interview survey in the Oarai Town office, the non-profit organization Oarai Umino Daigaku (Adventure Navigation Crew of Oarai), and Asunaro-kai in Kitaibaraki City. In addition, information was also gathered from a GIS analysis conducted jointly with the GIS Research Institute in Ibaraki. The authors would like to thank all those who participated for their cooperation. This research was supported by the Grant-in-Aid for Scientific Research (ID 22710042; 24510047).

\section{REFERENCES}

Central Disaster Prevention Council (2011). Expert examination committee report regarding earthquake/tsunami measures based on lessons from the 2011 Great East Japan Earthquake, September 28, 2011.

Fujimoto, K., Muroi, F., Suzuki, T., Kageshima, M. and Noto, T. (2012). "A study on Tsunami evacuation of coastal area in the northeastern part of Chiba Prefecture, Japan: Based on questionnaire surveys of Tsunami evacuation for coastal residents in Choshi city, Chiba Prefecture during the 2011 off the Pacific Coast of Tohoku Earthquake and the 2010 Chile Earthquake." Journal of Natural Disaster Science, Vol. 31, No. 1, 23-33.

Geospatial Information Authority of Japan (2011). 1:100,000 general map of inundated areas, http://www.gsi.go.jp/kikaku/kikaku60003.html

Hayakawa, S. and Imamura, F. (2002). "Model of the determination of tsunami evacuation and its application." Journal of Natural Disaster Science, Vol. 21, No. 1, 51-66. 
Hayashi, C. (1953). "Multidimensional quantification with the applications to analysis of social phenomena." Annals of the Institute of Statistical Mathematics, Vol. 5, No. 1, 121-143.

Hirose, H. (1984). Disaster science for survival: Nature, human, and civilization, Shin-yo-sha.

Ibaraki Prefecture (2007). Map showing areas with the potential for tsunami inundation for Ibaraki Prefecture, http://www.pref.ibaraki.jp/bukyoku/doboku/01 class/class06/tsunami/index.html

Ibaraki Prefecture (2011). Major earthquake-related disaster in Ibaraki Prefecture, http://www.pref.ibaraki.jp/bukyoku/seikan/kikikanri/bousai24.4.10/jisinsaigai.htm

Ibaraki Prefecture (2012a). Result of questionnaires concerning revision of the local disaster management plan of Ibaraki Prefecture in 2011, Fire and Disaster Management section, Living and Environment Department, Ibaraki prefectural government.

Ibaraki Prefecture (2012b). Map showing areas with the potential for tsunami inundation for Ibaraki Prefecture, http://www.pref.ibaraki.jp/bukyoku/doboku/01class/class06/kaigan/tsunamisinnsui/12shinsui.html

Ibaraki University (2011). Report on the survey of the 2011 Great East Japan Earthquake: Revised version, August 2011.

Inoue, H. (2011). "Why did Oarai town announce "Evacuate"? Case reports of evacuation-call expressions used for governmental disaster prevention wireless broadcasts." Broadcasting Research and Investigations, September 2011, 38-53.

Ito, T., Haraguchi, Y., Inui, Y., Gunji, H. and Tamura, M. (2011). "Evacuation activities/life at evacuation sites." Report on the survey of the 2011 Great East Japan Earthquake: Revised version, Ibaraki University, August 2011, 68-84.

Katada, T. (2011). "Tsunami disaster management education in Kamaishi City." JSCE Magazine “Civil Engineering,” Vol. 96, No. 8, 23-28.

Katada, T., Kodama, M., Kuwasawa, N. and Koshimura, S. (2005). "Issues of resident's consciousness and evacuation from the tsunami: From questionnaire survey in Kesennuma City, Miyagi Pref." Journal of JSCE, Vol. 789, No. II-71, 93-104.

Kawasaki, T., Murao, O., Isagawa, T. and Ohno, R. (2012). "Comparative analysis of the evacuation by an estimated Tsunami and the 2011 off the Pacific coast of Tohoku Earthquake in case of Onjuku, Chiba." Journal of Japan Association for Earthquake Engineering, Vol. 12, No. 4, 263-277.

Kitaibaraki Shinsaiki Henshu Iinkai (2012). Record of the disaster in Kitaibaraki (Kitaibaraki Shinsaiki), Editorial committee of a record of the disaster in Kitaibaraki (Kitaibaraki Shinsaiki Henshu Iinkai).

Lachman, R., Tatsuoka, M. and Bonk, W. J. (1961). "Human behavior during the Tsunami of 1960." Science, 1405-1409.

Lovholt, L., Kaiser, G., Glimsdal, S., Scheele, L., Harbitz, C. B. and Pedersen, G. (2012). "Modeling propagation and inundation of the 11 March 2011 Tohoku tsunami." Natural Hazards and Earth System Sciences, Vol. 12, No. 4, 1017-1028.

Meteorological Agency (2011). Bulletin of earthquake and tsunami in disaster, the 2011 off the Pacific coast of Tohoku Earthquake, Report on natural phenomena in disaster situations by the Meteorological Agency, Vol. 1.

Mimura, N., Yasuhara, K., Kawagoe, S., Yokoki, H. and Kazama, S. (2011). "Damage from the Great East Japan Earthquake and Tsunami: A quick report." Mitigation and Adaptation Strategies for Global Change, Vol. 16, No. 7, 803-818.

MLIT (Ministry of Land, Infrastructure, Transport, and Tourism) (2013). Results of surveys on the current state of tsunami damage from the 2011 Great East Japan Earthquake (third report), April, 2013.

Nobuoka, H., Uzaki, K., Matsuura, T. and Nabetani, Y. (2011). "Tsunami disaster in north part of Ibaraki Prefecture due to the 2011 Tohoku Pacific Ocean Earthquake." Journal of Japan Society of Civil Engineers, Ser. B2 (Coastal Engineering), Vol. 67, No. 2, I_1286-I_1290.

Post, J., Wegscheider, S., Muck, M., Zosseder, K., Kiefl, R., Steinmetz, T. and Strunz, G. (2009). "Assessment of human immediate response capability related to tsunami threats in Indonesia at a 
sub-national scale." Natural Hazards and Earth System Sciences, Vol. 9, No. 4, 1075-1086.

Satio, T. and Kagami, H. (2005). "Simulation of evacuation behavior from tsunami utilizing multi agent system: A case study of Aonae, Okushiri Island." Journal of Architecture and Planning, No. 597, 229-234.

Suppasri, A., Koshimura, S., Imai, K., Mas, E., Gokon, H., Muhari, A. and Imamura, F. (2012). "Damage characteristics and field survey of the 2011 Great East Japan Tsunami in Miyagi Prefecture." Coastal Engineering Journal, Vol. 54, No. 1, 1250005 (30 Pages).

Tamura, M. (2012). "Vulnerability to disasters and climate change: A case study of Ibaraki Prefecture following the 2011 Great East Japan Earthquake." International Perspectives in Victimology, Vol. 6, No. 2, 93-104.

Tanaka, S., Tabuchi, R., Kimura, R. and Wu, G. (2006). "Tsunami evacuation reconsidered." Journal of Japan Society for Natural Disaster Science, Vol. 25, No. 2, 183-195.

Weathernews Inc. (2011). Results of a survey on the tsunami of the Great East Japan Earthquake, http://weathernews.com/jp/c/press/2011/pdf/20110908_1.pdf, September 8, 2011.

Wegscheider, S., Post, J., Zosseder, K., Muck, M., Strunz, G., Riedlinger, T., Muhari, A. and Anwar, H. Z. (2011). "Generating tsunami risk knowledge at community level as a base for planning and implementation of risk reduction strategies." Natural Hazards and Earth System Sciences, Vol. 11, No. 2, 249-258.

Yamori, K. (2009). "Revisiting the concept of normalcy bias." Japanese Journal of Experimental Social Psychology, Vol. 48, No. 2, 137-149.

(Original Japanese Paper Published: August, 2013) (English Version Submitted: January 30, 2014)

(English Version Accepted: April 1, 2014) 